\title{
Inhibition of Endogenous Nitric Oxide Synthase Augments Contractile Response to Adenylyl Cyclase Stimulation Without Altering Mechanical Efficiency in Patients With Idiopathic Dilated Cardiomyopathy
}

\author{
Soichiro Ohta, MD; Toshiro Shinke, MD; Katsuya Hata, MD; Hideyuki Takaoka, MD; \\ Junya Shite, MD; Yoichi Kijima, MD; Takeomi Murata, MD; Ryohei Yoshikawa, MD; \\ Hiroyuki Masai, MD; Ken-ichi Hirata, MD; Mitsuhiro Yokoyama, MD
}

\begin{abstract}
Background Increased nitric oxide (NO) in the failing heart attenuates the myocardial contractile response to $\beta$-adrenergic receptor stimulation. However, the physiological effects of $\mathrm{NO}$ on the $\beta$-adrenergic post-receptor signaling system are unknown. The objective of the present study was to examine the effects of cardiac NO synthase (NOS) inhibition on left ventricular (LV) hemodynamics and mechanoenergetics in response to adenylyl cyclase stimulation in human heart failure.

Methods and Results The study group comprised 13 patients with heart failure because of idiopathic cardiomyopathy (IDC). Emax was examined as an index of LV contractility, LV external work (EW), pressure-volume area (PVA), myocardial oxygen consumption $\left(\mathrm{MV}^{\circ} \mathrm{O}_{2}\right)$, and mechanical efficiency (EW/MVO 2 ) with the use of conductance and coronary sinus thermodilution catheters before and during colforsin daropate infusion, and during concurrent infusion of colforsin daropate with the NOS inhibitor, $\mathrm{N}^{\mathrm{G}}$-monomethyl-L-arginine (L-NMMA; $200 \mu \mathrm{mol})$. Colforsin daropate increased Emax by $53 \%$ and EW by $18 \%$, and reduced PVA by $14 \%$, without altering $\mathrm{MVO}_{2}$ or mechanical efficiency. The combination of colforsin daropate with L-NMMA further increased Emax by $26 \%$ and reduced PVA by $9 \%$, without altering $\mathrm{MV}_{2}$ or mechanical efficiency.

Conclusions These findings suggest endogenous NO may modulate $\beta$-adrenergic post-receptor pathways and preserve myocardial efficiency in patients with IDC. (Circ J 2007; 71: 1268-1273)
\end{abstract}

Key Words: Adenylyl cyclase; Contractility; Heart failure; Nitric oxide

$\mathbf{N}$ itric oxide (NO) is an important regulator of cardiac function!,2 In patients with congestive heart failure (CHF) the concentrations of NO and tumor necrosis factora increase in proportion to the severity of heart failure 3,4 Previous studies have shown that inhibition of cardiac NO synthase (NOS) augments the positive inotropic response to $\beta$-adrenergic receptor stimulation in human heart failure, suggesting that increased activity of myocardial NOS and NO attenuates $\beta$-adrenergic responsiveness. ${ }^{5-7}$

In patients with severe $\mathrm{CHF}$, the increase in intracellular cyclic AMP and myocardial contractility in response to $\beta$ adrenergic receptor stimulation is reduced, which reflects cardiac desensitization to $\beta$-receptor agonists, partly modulated by the increased production of NO in the myocardium? Previous studies have shown that forskolin produces beneficial cardiac effects by directly stimulating adenylyl cyclase in the failed human heart, especially in those with a relative insensitivity to $\beta$-adrenergic receptor stimulation? Colforsin daropate (NKH477; 6-(3-dimethyl-aminopropionyl) forskolin

(Received September 20, 2006; revised manuscript received April 16, 2007; accepted April 25, 2007)

Division of Cardiovascular and Respiratory Medicine, Department of Internal Medicine, Kobe University, Graduate School of Medicine, Kobe, Japan

Mailing address: Toshiro Shinke, MD, Division of Cardiovascular and Respiratory Medicine, Department of Internal Medicine, Kobe University, Graduate School of Medicine, 7-5-1 Kusunoki-cho, Chuo-ku, Kobe 650-0017, Japan. E-mail: shinke@ med.kobe-u.ac.jp hydrochloride) is a new water-soluble forskolin derivative, which experimental studies have shown to be able to generate positive inotropic and vasodilatory actions! $!^{10,11}$ Furthermore, we previously reported that NKH477 might be a superior alternative to dobutamine for mechanical energy transduction in patients with left ventricular (LV) systolic dysfunction! ${ }^{2}$

It remains to be clarified how NO modulates $\beta$-adrenergic post-receptor signaling, such as adenylyl cyclase stimulation in the failing human heart. The objective of this study was to address the role of NO by evaluating the effects of cardiac NOS inhibition on LV hemodynamics and mechanoenergetics in response to adenylyl cyclase stimulation with colforsin daropate in patients with idiopathic cardiomyopathy (IDC).

\section{Methods}

\section{Study Subjects}

We examined 13 patients ( 10 men, 3 women, mean age $56 \pm 13$ years) who were undergoing diagnostic cardiac catheterization for the evaluation of heart failure on their first admission to hospital. All patients showed normal sinus rhythm and were diagnosed as IDC by the absence of coronary artery disease or other known causes of dilated cardiomyopathy. The patients were in New York Heart Association functional class II $(n=8)$ or class III $(n=5)$ with a LV ejection fraction (LVEF) of less than $40 \%$. None of 
A

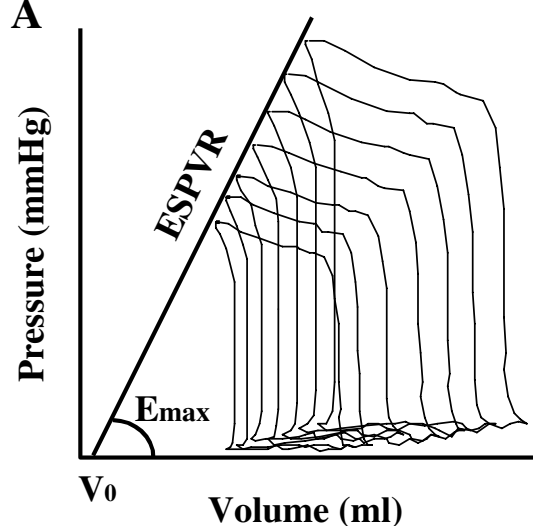

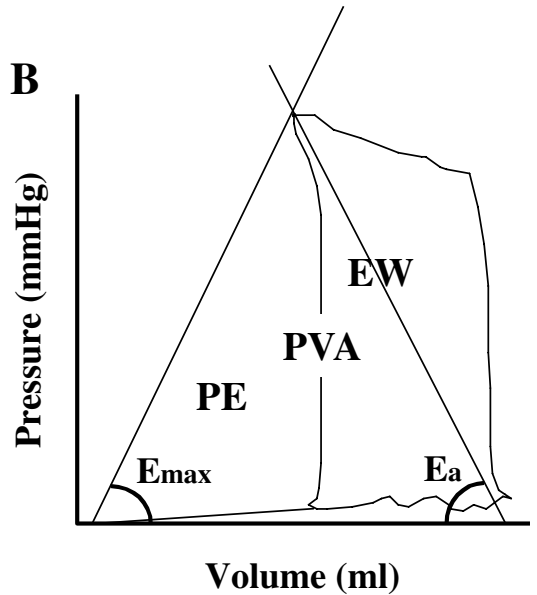

Fig 1. (A) Pressure-volume loops obtained with a conductance catheter during inferior vena cava occlusion. End-systolic pressure-volume relation (ESPVR) was obtained with linear least-squares fitting of end-systolic pressure-volume points when preload was reduced with inferior vena cava occlusion. $\mathrm{V}_{0}$ indicates volume intercept of ESPVR. (B) External work (EW) was calculated as the area bounded by the pressure-volume trajectory of steady state 1 beat. Systolic pressure-volume area (PVA) was calculated as the area bounded by the end-systolic and end-diastolic pressure-volume relationships and the systolic pressure-volume trajectory of each beat. Potential energy (PE) was calculated by substracting EW from PVA. the patients were taking $\beta$-blockers at the time of catheterization, and angiotensin-converting enzyme inhibitors (ACEI) were withheld at least $48 \mathrm{~h}$ before the study. Complete informed, written consent was given by each patient before the study. No unfavorable complications occurred as a result of this investigation. The study protocol was approved by the Institutional Committee on Human Research at Kobe University Hospital.

\section{Catheterization Procedure}

Cardiac catheterization was performed with the femoral approach and the patient in a fasting state. After routine right and left heart catheterization was completed, a 7F thermodilution Swan-Ganz catheter (Goodtech Inc, LA) was advanced to the pulmonary artery through the right femoral vein for measurements of cardiac index (CI) and pulmonary artery wedge pressure (PAWP), and an 8F conductance (volume) catheter (CardioDynamics, Rijnsberg, The Netherlands) was advanced into the LV through the right femoral artery. The conductance catheter was attached to a stimulator/processor (Sigma-5; CardioDynamics), and a 2F Millar catheter (Millar Instruments, Houston, TX, USA) was advanced into the LV through the lumen of the conductance catheter. Continuous slow infusion of heparinized saline solution through the lumen of the conductance catheter was maintained to prevent hemostasis. A 4F Judkins catheter was advanced to the ostium of the left main coronary artery via the right femoral artery for intracoronary drug infusion and was continuously flushed with saline containing heparin. An $8 \mathrm{~F}$ coronary sinus thermodilution catheter (Cordis Webster, Inc, Diamond Bar, CA, USA) was then advanced into the coronary sinus through the right jugular vein. A large balloon occlusion catheter (Baxter, Deerfield, IL, USA) was advanced to the right atrium through the right femoral vein to achieve occlusion of the inferior vena cava.

\section{Assessment of LV Contractility}

After calibrations were completed, a balloon catheter (Baxter) was advanced to the right atrium just above the inferior vena cava to interrupt venous return. After a reduction in the preload resulting in a 30 - to $40-\mathrm{mmHg}$ decrease in LV systolic pressure (LVSP), pressure-volume loops for the sequence of beats were recorded over $8-10$ beats. This procedure was repeated several times to exclude extra-systolic and post extra-systolic beats and to obtain the stable end-systolic pressure-volume relation (ESPVR) (Fig 1A). ESPVR were fitted using the linear least-squares technique during a transient decrease in LV pressure to determine:

$$
\mathrm{ESP}=\mathrm{Emax}\left(\mathrm{ESV}-\mathrm{V}_{0}\right)
$$

where ESP is the LV end-systolic pressure, Emax is the slope of the linear end-systolic pressure-volume relationship, ESV is the end-systolic LV volume and $\mathrm{V}_{0}$ is the intercept of the volume axis. Then, the volume of end-systolic elastance at a pressure of $100 \mathrm{mmHg}\left(\mathrm{V}_{100}\right)$ is calculated. Emax $(\mathrm{mmHg} / \mathrm{ml})$ has previously been applied to the LV of the intact animal and human heart as a load-independent index of myocardial contractility! 3,14 We normalized Emax $(\mathrm{mmHg}$. $\left.\mathrm{ml}^{-1} \cdot \mathrm{m}^{-2}\right)$ and $\mathrm{V}_{100}\left(\mathrm{ml} / \mathrm{m}^{2}\right)$ in relation to body surface area, as described previously, ${ }^{14}$ to permit comparison among patients in our study.

\section{Effective Arterial Elastance $\left(E_{a}\right)$ and Arterial-Ventricular Coupling}

We determined effective $\mathrm{E}$ a, a variable that incorporates the values of Windkessel model elements and heart rate as the ratio of end-systolic pressure to stroke volume ${ }^{15}$ as follows:

\section{$\mathrm{E}_{\mathrm{a}}=\mathrm{ESP} / \mathrm{SV}$}

where ESP is the LV end-systolic pressure, SV is the stroke volume, and $\mathrm{E}_{\mathrm{a}}$ is the negative value of the slope of the diagonal line connecting the end-systolic pressure-volume point and the end-diastolic point on the volume axis (Fig 1B). The dimensionless ratio of $\mathrm{E}_{\mathrm{a}}$ to $\mathrm{E}_{\max }\left(\mathrm{Ea} / \mathrm{E}_{\max }\right)$ represents arterial-ventricular coupling.

\section{Calculation of Pressure-Volume Area (PVA)}

The systolic PVA $(\mathrm{mmHg} / \mathrm{ml})$ was calculated as the area that is bounded by the end-systolic and end-diastolic pressure-volume relationships and the systolic pressurevolume trajectory of each beat ${ }^{13}$ PVA consists of external work (EW) and potential energy (PE) and is considered to represent the total mechanical energy generated by contraction. EW was calculated as the area that is surrounded by the pressure-volume trajectory during 1 cardiac cycle and PE by subtracting EW from PVA (Fig 1B).

\section{Measurements of Cardiac Mechanoenergetics}

The coronary sinus catheter was advanced percutaneously through the right jugular vein to the great cardiac vein. In 
Table 1 Effects of Colforsin Daropate Alone and in Combination With L-NMMA on Hemodynamic Variables

\begin{tabular}{|c|c|c|c|}
\hline & Control & Colf & Colf $+L-N M M A$ \\
\hline Heart rate, beats/min & $94 \pm 7$ & $94 \pm 7$ & $95 \pm 8$ \\
\hline LVSP, $m m H g$ & $131 \pm 16.2$ & $133.8 \pm 22.6$ & $134.1 \pm 19.0$ \\
\hline LVEDP, $\mathrm{mmHg}$ & $16.2 \pm 7.6$ & $13.5 \pm 6.1 *$ & $14.4 \pm 6.6^{* \dagger}$ \\
\hline$P A W P, m m H g$ & $9.4 \pm 6.2$ & $5.7 \pm 5.8^{*}$ & $6.5 \pm 7.0$ \\
\hline$C I, L \cdot \mathrm{min}^{-1} \cdot \mathrm{m}^{-2}$ & $2.96 \pm 0.52$ & $3.86 \pm 0.87 *$ & $3.54 \pm 0.89 *$ \\
\hline$E D V I, \mathrm{ml} / \mathrm{m}^{2}$ & $87.3 \pm 21.9$ & $71.4 \pm 24.3^{*}$ & $66.2 \pm 25.8^{*}+\dagger$ \\
\hline$E S V I, \mathrm{ml} / \mathrm{m}^{2}$ & $68.2 \pm 24.6$ & $51.9 \pm 26.3 *$ & $48.7 \pm 27.0^{* \dagger}$ \\
\hline$S V I, m l / m^{2}$ & $19.2 \pm 8.0$ & $19.5 \pm 7.6$ & $17.5 \pm 6.3^{\dagger}$ \\
\hline$E F, \%$ & $23.3 \pm 11.1$ & $30.5 \pm 14.7^{*}$ & $30.5 \pm 15.5^{*}$ \\
\hline Peak $+d P / d t, m m H g / s$ & $1,323 \pm 331$ & $1,634 \pm 415^{*}$ & $1,669 \pm 409 *$ \\
\hline$d P / d t / E D V, m m H g \cdot s^{-1} \cdot m l^{-1}$ & $10 \pm 3.0$ & $15.7 \pm 6.1 *$ & $17.8 \pm 8.8 * \dagger$ \\
\hline SVR, dyne $\cdot \mathrm{s}^{-1} \cdot \mathrm{cm}^{-5}$ & $1,576 \pm 547$ & $1,256 \pm 694 *$ & $1,401 \pm 614^{*}+$ \\
\hline CSF, $\mathrm{ml} / \mathrm{min}$ & $103 \pm 26$ & $133 \pm 26 *$ & $128 \pm 28^{\dagger}$ \\
\hline$M \dot{V} \mathrm{O}_{2}, \mathrm{~J} / \mathrm{min}$ & $267 \pm 66$ & $280 \pm 67$ & $290 \pm 67$ \\
\hline
\end{tabular}

L-NMMA, $N^{G}$-monomethyl-L-arginine; Colf, colforsin daropate; LVSP, left ventricular systolic pressure; LVEDP, left ventricular end-diastolic pressure; PAWP, mean pulmonary arterial wedge pressure; CI, cardiac index; EDVI, left ventricular end-diastolic volume index; ESVI, left ventricular end-systolic volume index; SVI, left ventricular stroke volume index; EF, left ventricular ejection fraction; SVR, systemic vascular resistance; $C S F$, coronary sinus flow; $M \dot{V} O 2$, myocardial oxygen consumption per minute.

Values are mean $\pm S D$

${ }^{*} p<0.05$ vs Control; ${ }^{\dagger} p<0.05$ vs Colf.

each instance, the catheter tip was angiographically verified to have traveled beyond the origin of any visible intermediate or lateral branches and to be proximal to the anterior cardiac vein. Coronary sinus blood flow was measured at least twice using a coronary sinus catheter during a 30-s continuous injection with a Mark IV angiographic injector (Medrad, Indianola, IA, USA) of a room-temperature indicator (5\% glucose) through the catheter lumen at a rate of $40 \mathrm{ml} / \mathrm{min}{ }^{16}$ For oximetry, coronary venous blood was sampled from the distal lumen of the coronary sinus catheter. Myocardial oxygen consumption $\left(\mathrm{MV}^{\mathrm{V}} 2\right)$ per minute was calculated as the product of coronary sinus flow $(\mathrm{ml} / \mathrm{min})$ and the arterial-coronary sinus oxygen content difference ( $\operatorname{vol} \%)$, and was divided by the heart rate to yield $\mathrm{MV}_{2}$ per beat $\left(\mathrm{ml}^{\cdot} \mathrm{O}_{2}{ }^{-1} \text {. beat }{ }^{-1}\right) !^{4,16}$ We calculated mechanical efficiency as the ratio of $\mathrm{EW}$ (J/beat) to $\mathrm{MVO}_{2}$ per beat (J/beat), where $1 \mathrm{mmHg} / \mathrm{ml}$ of $\mathrm{EW}$ corresponds to $1.33 / 10^{-4} \mathrm{~J}$ and $1 \mathrm{ml} \mathrm{O}_{2}$ of oxygen consumption to $20 \mathrm{~J}$. Mechanical efficiency is thus dimensionless. We determined the mechanical efficiency as a measure of the overall energy conversion efficiency of each study protocol.

\section{Study Protocol}

Control Study After routine cardiac catheterization, right atrial pacing was initiated by the tipped electrode of the coronary sinus thermodilution catheter at 90 or 20 beats/min above the baseline heart rate and continued throughout the study $(94 \pm 7$ beats $/ \mathrm{min})$. After steady-state hemodynamics was attained, hemodynamic variables, pressure-volume loops, and coronary sinus flow were measured and blood gas samples were collected from the coronary sinus and coronary arteries. Occlusion of the inferior vena cava was performed several times to calculate ESPVR.

Colforsin Daropate Study After completion of control measurements, continuous infusion of colforsin daropate was started at a rate of $0.5 \mu \mathrm{g} \cdot \mathrm{kg}^{-1} \cdot \mathrm{min}^{-1}$ for $30-45 \mathrm{~min}$ via a systemic vein. After steady hemodynamic and contractile states had been attained, we made measurements similar to those for the control study.

Colforsin Daropate/L-NMMA Study While the colforsin daropate infusion continued, the intracoronary infusion of L-NMMA, an NOS inhibitor, was started through a Judkins catheter advanced to the left main coronary artery. The infusion rate was $20 \mu \mathrm{mol} / \mathrm{min}$ for $10 \mathrm{~min}$. The same measurements as for the colforsin daropate study were then performed to assess how NO inhibition affects the response to colforsin daropate. We previously reported that intracoronary infusion of L-NMMA alone does not affect LV hemodynamics or mechanoenergetics in patients with IDC?

\section{Statistical Analysis}

Data are presented as mean $\pm \mathrm{SD}$, unless otherwise indicated. ESPVR lines were obtained by the application of linear regression analysis. The effects of colforsin daropate alone and in combination with L-NMMA were analyzed independently with a paired t-test with Bonferroni correction. Differences were considered significant at $\mathrm{p}<0.05$.

\section{Results}

Effects of Colforsin Daropate Alone and in Combination With L-NMMA on Systemic and Coronary Hemodynamic Variables (Tables 1,2)

Colforsin daropate produced an increase in CI, peak $+\mathrm{dP} / \mathrm{dt}$ and $\mathrm{dP} / \mathrm{dt} / \mathrm{EDV}$ (by $30 \%, 24 \%$ and $57 \%$, respectively), and a decrease in LV end-diastolic pressure (LVEDP), PAWP and systemic vascular resistance (SVR) (by 13\%, $35 \%$ and $23 \%$, respectively), without any significant changes in LVSP. When colforsin daropate was administered, the LV end-diastolic volume index (LVEDVI) and LV end-systolic volume index decreased by $20 \%$ and $27 \%$, respectively, and as a result, the LV stroke volume index did not change significantly even though the LVEF improved $23.3 \%$ to $30.5 \%(\mathrm{p}=0.0043)$. Compared with colforsin daropate infusion alone, intracoronary infusion of L-NMMA+colforsin daropate increased dP/dt/EDV, LVEDP and SVR by $10 \%$, $8 \%$ and $18 \%$, respectively, without changing LVSP, PAWP, CI or peak $+\mathrm{dP} / \mathrm{dt}$. Colforsin daropate alone and in combination with L-NMMA increased $\mathrm{MV}_{2} 2$ slightly but without statistical significance.

Effects of Colforsin Daropate Alone and in Combination With L-NMMA on Mechanoenergetic Variables (Table 2)

The LV ESPVR was successfully assessed in 10 of the 13 
Table 2 Effects of Colforsin Daropate Alone and in Combination With L-NMMA on Mechanoenergetic Variables

\begin{tabular}{|c|c|c|c|}
\hline & Control & Colf & Colf $+L-N M M A$ \\
\hline$E_{\max }, m m H g \cdot m l^{-1} \cdot m^{-2}$ & $2.70 \pm 0.84$ & $4.20 \pm 1.88^{*}$ & $5.20 \pm 2.63 *, t$ \\
\hline$E_{a}, m m H g \cdot m l^{-1} \cdot m^{-2}$ & $7.37 \pm 3.59$ & $7.40 \pm 3.63$ & $7.93 \pm 3.40$ \\
\hline Coupling & $2.87 \pm 1.60$ & $1.97 \pm 1.16^{*}$ & $1.84 \pm 1.23^{*}$ \\
\hline$V_{100} \mathrm{ml} / \mathrm{m}^{2}$ & $52.2 \pm 27.1$ & $40.9 \pm 27.4^{*}$ & $34.6 \pm 30.3 * t$ \\
\hline$P V A, J / m^{2}$ per beat & $0.70 \pm 0.19$ & $0.60 \pm 0.20 *$ & $0.55 \pm 0.18 * \dagger$ \\
\hline$E W, J / m^{2}$ per beat & $0.28 \pm 0.11$ & $0.32 \pm 0.10^{*}$ & $0.31 \pm 0.12 *$ \\
\hline$P E, J / m^{2}$ per beat & $0.42 \pm 0.12$ & $0.29 \pm 0.13^{*}$ & $0.23 \pm 0.12 * \dagger$ \\
\hline$E W / P V A, \%$ & $39.5 \pm 9.1$ & $53.9 \pm 11.0 *$ & $59.0 \pm 12.8^{*}$ \\
\hline$M \dot{V} O_{2}$, J per beat & $2.86 \pm 0.70$ & $2.98 \pm 0.72$ & $3.06 \pm 0.69$ \\
\hline$E W / M \dot{V} O_{2}, \%$ & $17.7 \pm 11.0$ & $18.2 \pm 8.5$ & $17.8 \pm 8.5$ \\
\hline
\end{tabular}

Emax, slope of left ventricular end-systolic pressure-volume relation; Ea, effective arterial elastance; Coupling, arterial-ventricular coupling; V100, end-systolic volume at a pressure of $100 \mathrm{mmHg} ; P V A$, systolic pressure volume area; $E W$, external work; PE, potential energy. Other abbreviations see in Table 1.

Values are mean $\pm S D$.

${ }^{*} p<0.05$ vs Control; ${ }^{\dagger} p<0.05$ vs Colf.

A

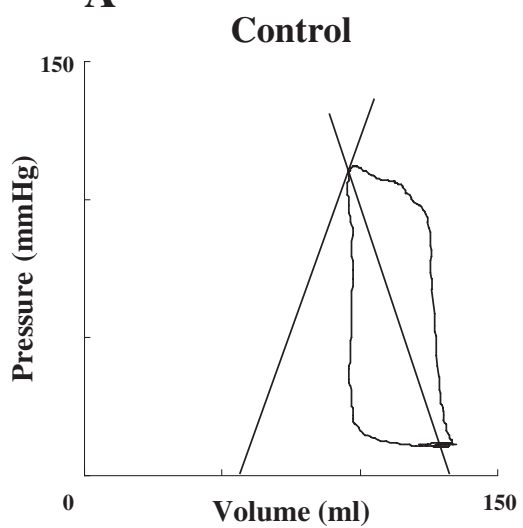

B

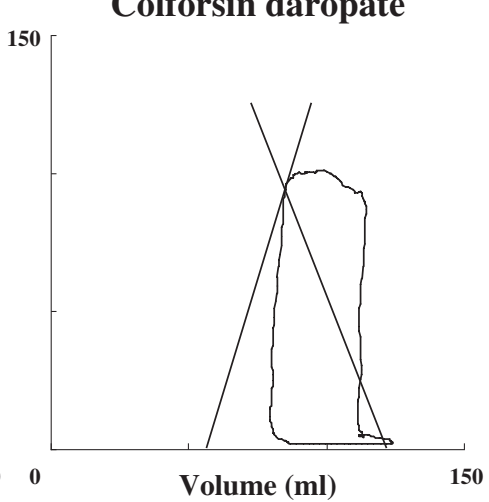

C

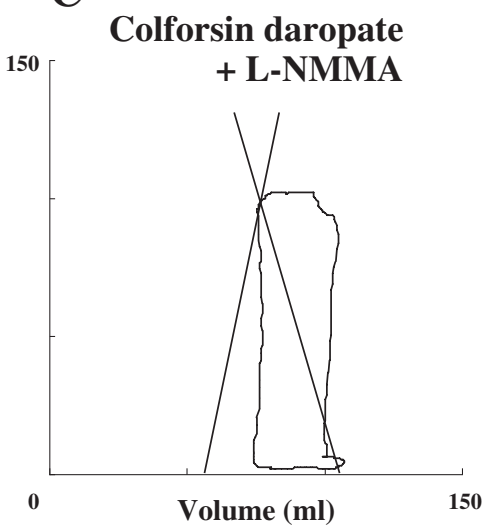

Fig 2. Representative pressure-volume loops. (A) Control: Emax $=4.41 \mathrm{mmHg} \cdot \mathrm{ml}^{-1} \cdot \mathrm{m}^{-2} ; \mathrm{Ea}=5.45 \mathrm{mmHg} \cdot \mathrm{ml}^{-1} \cdot \mathrm{m}^{-2}$; $\mathrm{EW}=0.21 \mathrm{~J} / \mathrm{m}^{2} ; \mathrm{PVA}=0.40 \mathrm{~J} / \mathrm{m}^{2}$. (B) Colforsin daropate: $\mathrm{Emax}=5.02 \mathrm{mmHg} \cdot \mathrm{ml}^{-1} \cdot \mathrm{m}^{-2} ; \mathrm{Ea}=4.63 \mathrm{mmHg} \cdot \mathrm{ml}^{-1} \cdot \mathrm{m}^{-2} ; \mathrm{EW}=$ $0.23 \mathrm{~J} / \mathrm{m}^{2} ; \mathrm{PVA}=0.31 \mathrm{~J} / \mathrm{m}^{2}$. (C) Colforsin daropate $+\mathrm{L}-\mathrm{NMMA}:$ Emax $=6.46 \mathrm{mmHg} \cdot \mathrm{ml}^{-1} \cdot \mathrm{m}^{-2} ; \mathrm{Ea}=6.08 \mathrm{mmHg} \cdot \mathrm{ml}^{-1} \cdot \mathrm{m}^{-2}$; $\mathrm{EW}=0.22 \mathrm{~J} / \mathrm{m}^{2} ; \mathrm{PVA}=0.30 \mathrm{~J} / \mathrm{m}$. Ea, effective arterial elastance; Emax, slope of the linear end-systolic pressure-volume relationship EW, external work; L-NMMA, NG-monomethyl-L-arginine; PVA, pressure-volume area.

patients, but in the remaining 3 patients, the protocol could not be completed because pressure-volume measurement during inferior vena cava occlusion was not successful. Colforsin daropate alone increased Emax by $53 \%$ with a leftward shift of $\mathrm{V}_{100}$ and without causing any changes in $\mathrm{Ea}$, and improved arterial-ventricular coupling by $31 \%$. It also increased EW by $18 \%$ and reduced PVA by $14 \%$ and $\mathrm{PE}$ by $35 \%$, resulting in an increase in the EW/PVA ratio from $39.5 \%$ to $53.9 \%(\mathrm{p}<0.05)$, but no changes in $\mathrm{MV}_{2}$ or the EW/MVंO2 ratio. Intracoronary infusion of L-NMMA combined with colforsin daropate produced a further increase in Emax by $26 \%$ over that effected by colforsin daropate alone, with a leftward shift of $\mathrm{V}_{100}$ and without any changes in $\mathrm{Ea}$ or arterial-ventricular coupling. The combined infusion also reduced PVA by $9 \%$ and PE by $19 \%$, in addition to the reduction effected by colforsin daropate alone, but produced no changes in EW, the EW/PVA ratio, $\mathrm{MVO}_{2}$ or the $\mathrm{EW} / \mathrm{MVO}_{2}$ ratio.

Fig 2 shows the pressure-volume loops of a representative case entered in our study. In this case, colforsin daropate alone increased Emax (Figs 2A,B) and concurrent infusion of L-NMMA with colforsin daropate produced an additional increase in Emax (Fig 2C).

\section{Discussion}

We examined the effects of cardiac NOS inhibition on LV mechanoenergetics in response to adenylyl cyclase stimulation with colforsin daropate in patients with IDC. The major findings of our study are that (1) colforsin daropate increased Emax and EW, and reduced PVA and PE without producing any changes in $\mathrm{MVO}_{2}$ or mechanical efficiency and (2) the combination of colforsin daropate with L-NMMA effected an additional increase in Emax, and reduced PVA and PE without changing EW, $\mathrm{MVO}_{2}$ or mechanical efficiecy. These results suggest that endogenous NO may modulate the myocardial contractile response to adenylyl cyclase stimulation and energetics in human heart failure.

NO is synthesized from L-arginine by NOS, and endogenous NO in cardiomyocytes performs important roles in the regulation of myocardial function, ${ }^{1,2} \mathrm{NO}$ can increase or decrease myocardial contractility, depending on the preparation and conditions! Many factors modulate the net effect of NO on myocardial function: NO concentration, cGMPdependent or -independent signaling pathway ${ }^{17}$ adrenergic state, NO species, targets affected by NO such as calcium cycling 18 and excitation-contraction coupling (E-C cou- 
pling), as well as the NOS isoforms ${ }^{19}$

In our study, we found that intracoronary infusion of a NOS inhibitor augmented the positive inotropic response to colforsin daropate, which suggests that NO may also exert its effect by modulating $\beta$-adrenergic post-receptor signaling pathways in patients with IDC. Several mechanisms have been proposed for the inhibition of the positive inotropic response to adenylyl cyclase stimulation by NO. One such mechanism is based on the fact that NO activates soluble guanylyl cyclase by binding to its heme moiety, forming an Fe-nitrosyl complex, which leads to the production of cGMP. The latter inhibits the cAMP-stimulated slow inward $\mathrm{Ca}^{2+}$ channels through activation of protein kinase $\mathrm{G}$ and activates cGMP-dependent phosphodiesterase.20 Another mechanism is based on the fact that NO causes thiol nitrosylation of cellular proteins and formation of peroxynitrite ${ }^{21}$ Protein nitrosylation activates various proteins involved in E-C coupling, including the L-type $\mathrm{Ca}^{2+}$ channel and the ryanodine receptor.

An in-vitro study has demonstrated that the type 5 and 6 isoforms of adenylyl cyclase, which are preferentially expressed in cardiac myocytes, may be inhibited via direct nitrosylation by $\mathrm{NO}^{22}$ Because endothelial type NOS (NOS3), $\beta$-adrenergic receptors and adenylyl cyclase types 5 and 6 co-localize ${ }^{22}$ the effects of NO on myocardial contractility may partly depend on compartmentalization between NOS3 and $\mathrm{G}$ protein coupled $\beta$-adrenergic receptors 19,23

Investigation of the pathophysiology of heart failure requires a metabolic approach for the assessment of $\mathrm{MVO}_{2}$, as well as a functional approach. LV afterload, preload, and contractile state, as well as PVA as a determinant of $\mathrm{MV}_{2}$, all need to be taken into consideration. $\mathrm{MVO}_{2}$ consists of PVA-dependent $\mathrm{MVO}_{2}$ and of PVA-independent $\mathrm{MV}_{2}$ for $\mathrm{E}-\mathrm{C}$ coupling and basal metabolism. $\mathrm{MVO}_{2}$ for basal metabolism and the slope of the $\mathrm{MVO}_{2}$ - PVA relationship are assumed to be constant ${ }^{13}$ and PVA has been shown to linearly correlate with $\mathrm{MVO}_{2}{ }^{24}$ independent of loading conditions or contractile state. Thus, PVA has been proposed as a predictor of $\mathrm{MV}$ 2. In our study, colforsin daropate increased LV contractility and reduced PVA without causing any change in $\mathrm{MV}_{2}$. One of the reasons why colforsin daropate did not increase $\mathrm{MVO}$, despite its positive inotropic effect, is probably that colforsin daropate reduced the afterload including SVR and the preload including LVEDVI (Tables 1,2).

Previous studies have indicated that mitochondrial NO regulates energy metabolism. Zhang et al demonstrated in isolated myocardial slices from the dog heart that ACEIs increase nitrite production and reduce $\mathrm{MVO}_{2}$, suggesting that NO inhibits mitochondrial respiration.25 NOS inhibitors have been reported to increase $\mathrm{MVO}$ 27,26 In our study, NOS inhibition did not increase $\mathrm{MV}_{2}$ during inotropic enhancement via direct adenylyl cyclase stimulation, although the augmented positive inotropic response to colforsin daropate with L-NMMA probably increased PVA-independent $\mathrm{MVO}_{2}$, especially $\mathrm{MV}_{2}$ for E-C coupling. It seems reasonable to assume that a significant increase in Emax without an increase in $\mathrm{MV} \mathrm{O}_{2}$ during concurrent infusion of colforsin daropate with L-NMMA is a consequence of offseting an increase in PVA-independent $\mathrm{MVO}_{2}$ for $\mathrm{E}-\mathrm{C}$ coupling and a decrease in PVA-dependent $\mathrm{MV}_{2}$.

Nordhaug et al reported that inhibition of NOS in experimental acute ischemic heart failure displayed a significant increase in the slope of the $\mathrm{MVO}_{2}-\mathrm{PVA}$ relationship and increased afterload without altering LV contractility, suggesting that NOS plays a role in preserving myocardial efficiency ${ }^{27}$ Huang et al reported that NOS also has a protective effect against myocardial injury during ischemiareperfusion ${ }^{28}$ However, no data have been published to document the possible effects of NOS inhibition on the direct control of PVA-independent $\mathrm{MV}_{2}$ or $\mathrm{MV}_{2}$ for E-C coupling. Further studies are therefore warranted to examine the effect of cardiac NOS inhibition on PVA-independent $\mathrm{MVO}_{2}$ or $\mathrm{MV \dot {V }} 2$ for E-C coupling.

It has previously been reported that intracoronary infusion of L-NMMA at a rate of $20 \mu \mathrm{mol} / \mathrm{min}$ alone does not change the hemodynamics in humans with LV dysfunction $^{29}$ or the mechanoenergetic variables in patients with IDC? The lack of any effect of L-NMMA alone on LV contractility in heart failure suggests that NO produced by NOS is exerting its effect primarily by modulating $\beta$-adrenergic receptor signaling. Inhibition of cardiac NO does not enhance the positive inotropic response to $\beta$-adrenergic receptor stimulation in subjects with normal LV function? Identification and clarification of the cardiac effect of NO can be complicated by the systemic effect of the NOS inhibitor. By using direct intracoronary infusion of L-NMMA, we were able to observe the direct effect of selective inhibition of NOS in the myocardium. Moreover, the use of relatively load-independent indices, such as Emax, enabled us to circumvent changes in loading conditions that could have confounded the interpretation of the data. We did not have a control group in which vehicle solution was infused in place of L-NMMA. In addition, there remains the possibility that L-NMMA may directly affect the LV contractile response to colforsin daropate rather than NOS inhibition.

Addition of L-NMMA to colforsin daropate increased Emax, but decreased EDV with a slight increase in EDP. Upward shift of the end-diastolic pressure-volume loop during L-NMMA infusion may be partly induced by the right ventricular Bernheim effect, 30,31 which might decrease $\mathrm{SV}$; however, the inotropic enhancement with L-NMMA maintained LV EW with a decrease in PVA.

Potential errors related to the assumption of a linear ESPVR need to be taken into account. Kass et al suggested the possible existence of contractility-dependent curvilinearity of the ESPVR, 32 which may have been present in our study, but was not observed because of the relatively narrow range of alterations in loading conditions. Nevertheless, estimation of PVA by means of linear regression analysis of ESPVR has been reported to be a reliable predictor of $\mathrm{MV}_{2}$ under various contractile states in canine and human hearts 24

In conclusion, this study has demonstrated that inhibition of cardiac NOS enhanced the positive inotropic response to adenylyl cyclase stimulation without altering $\mathrm{MVO} 2$ or mechanical efficiency. Our findings suggest that NO attenuates the positive inotropic response to adenylyl cyclase stimulation and preserves myocardial efficiency in patients with IDC. The present data supports the known therapeutic efficacy of ACEIs ${ }^{25}$ or other non-pharmacological therapy ${ }^{33}$ that facilitates the bioavailability of NO for the treatment of heart failure.

\section{References}

1. Massion PB, Feron O, Dessy C, Balligand J-L. Nitric oxide and cardiac function: Ten years after, and continuing. Circ Res 2003; 93: $388-398$.

2. Belge C, Massion PB, Pelat M, Balligand J-L. Nitric oxide and the 
heart update on new paradigms. Ann NY Acad Sci 2005; 1047: $173-$ 182.

3. Winlaw DS, Smythe GA, Kegoh AM, Schyvens CG, Spratt PM, MacDonald PS. Increased nitric oxide production in heart failure. Lancet 1994; 344: 373-374.

4. Sugamori T, Ishibashi Y, Shimada T, Takahashi N, Sakane T, Ohata $\mathrm{S}$, et al. Increased nitric oxide in proportion to the severity of heart failure in patients with dilated cardiomyopathy: Close correlation of tumor necrosis factora with systemic and local production of nitric oxide. Circ J 2002; 66: 627-632.

5. Hare JM, Givertz MM, Creager MA, Colucci WS. Increased sensitivity to nitric oxide synthase inhibition in patients with heart failure: Potentiation of $\beta$-adrenergic inotropic responsiveness. Circulation 1998; 97: $161-166$

6. Ziolo MT, Maier LS, Piacentio V 3rd, Bossuyt J, Houser SR, Bers DM. Myocyte nitric oxide synthase 2 contributes to blunted $\beta$-adrenergic response in failing human hearts by decreasing $\mathrm{Ca}^{2+}$ transients. Circulation 2004; 109: 1886-1891.

7. Shinke T, Takaoka H, Takeuchi M, Hata K, Kawai H, Yokoyama M, et al. Nitric oxide spares myocardial oxygen consumption through attenuation of contractile response to $\beta$-adrenergic stimulation in patients with idiopathic dilated cardiomyopathy. Circulation 2000; 101: $1925-1930$.

8. Neumann J, Schmitz W, Schloz H, Meyerinck LV, Doring V, Kalma P. Increase in myocardial Gi-proteins in heart failure. Lancet 1988; 2: $936-937$.

9. Braumann G, Felix S, Sattelberger U, Klein G. Cardiovascular effects of forskolin (HL 362) in patients with idiopathic congestive cardiomyopathy: A comparative study with dobutamine and sodium nitroprusside. J Cardiovasc Pharmacol 1990; 16: 93-100.

10. Shafiq J, Suzuki S, Itoh T, Kuriyama H. Mechanism of vasodilation induced by NKH477, a water soluble forskolin derivative, in smooth muscle of the porcine coronary artery. Circ Res 1992; 71: 70-81.

11. Yoneyama M, Sugiyama A, Satoh Y, Takahara A, Nakamura Y, Hashimoto K. Cardiovascular and adenylate cyclase stimulating effects of colforsin daropate, a water-soluble forskolin derivative, compared with those of isoproterenol, dopamine and dobutamine. Circ J 2002; 66: 1150-1154.

12. Mori M, Takeuchi M, Takaoka H, Hata K, Hayashi Y, Yokoyama M. Effects of NKH477, a new water-soluble forskolin derivative, on arterial-ventricular coupling and mechanical energy transduction in patients with left ventricular systolic dysfunction: Comparison with dobutamine. J Cardiovasc Pharmacol 1994; 24: 310-316.

13. Suga H. Ventricular energetics. Physiol Rev 1990; 70: 247-277.

14. Grossman W, Braunwald E, Mann T, McLaurin LP, Green LH. Contractile state of the left ventricle in man as evaluated from end-systolic pressure-volume relation. Circulation 1977; 56: 845-852.

15. Sunagawa K, Maughan WL, Sagawa K. Optimal arterial resistance for the maximal stroke work studied in the isolated canine left ventricle. Circ Res 1985; 56: 586-595.

16. Baim DS, Rothman MT, Harrison DC. Simultaneous measurement of coronary venous blood flow and oxygen saturation during transient alterations in myocardial oxygen supply and demand. Am J Cardiol 1982; 49: 743-752.

17. Paolocci N, Ekelund UG, Isoda T, Ozaki M, Vandegaer K, Georgakopoulos D, et al. cGMP-independent inotropic effects of nitric oxide and peroxynitrite donors: Potential role for nitrosylation. Am J Physiol Heart Circ Physiol 2000; 279: H1982-H1988.

18. Khan SA, Skaf MW, Harrison RW, Lee K, Minhas KM, Kumar A, et al. Nitric oxide regulation of myocardial contractility and calcium cycling: Independent impact of neuronal and endothelial nitric oxide synthases. Circ Res 2003; 92: 1322-1329.

19. Barough LA, Harison RW, Skaf MW, Rosas GO, Cappola TP, Kobeissi ZA, et al. Nitric oxide regulates the heart by spatial confinement of nitric oxide synthase isoforms. Nature 2002; 416: 337-340.

20. Mery PF, Pavoine C, Belhassen L, Pecker F, Fishmeister R. Nitric oxide regulates cardiac $\mathrm{Ca}^{2+}$ current. J Biol Chem 1993; 268: 26286-26295.

21. Stamler JS. Redox signaling: Nitrosylation and related target interactions of nitric oxide. Cell 1994; 78: 931-936.

22. Ostrom RS, Bundey RA, Insel PA. Nitric oxide inhibition of adenylyl cyclase type 6 activity is dependent upon lipid rafts and caveolin signaling complexes. J Biol chem 2004; 279: 19846-19853.

23. Hare JM, Lofthouse GJ, Colman JL, Ricker KM, Kim B, Senzaki H, et al. Contribution of caveolin protein abundance to augmented nitric oxide signaling in conscious dogs with pacing-induced heart failure. Circ Res 2000; 86: 1085-1092.

24. Takaoka H, Takeuchi M, Odake M, Hayashi Y, Hata K, Yokoyama $\mathrm{M}$, et al. Comparison of hedynamic determinants for myocardial oxygen consumption under different contractile states in human ventricle. Circulation 1993; 87: 59-69.

25. Zhang X, Xie YW, Nasjletti A, Xu X, Wolin MS, Hintze TH. ACE inhibitors promote nitric oxide accumulation to modulate myocardial oxygen consumption. Circulation 1997; 95: 176-182.

26. Saavedra WF, Paolocci N, St John ME, Skaf MW, Stewart GC, Xie JS, et al. Imbalance between xanthine oxidase and nitric oxide synthase signaling pathways underlies mechanoenergetic uncoupling in the failing heart. Circ Res 2002; 90: 297-304.

27. Nordhaug D, Steensrud T, Aghajani E, Korvald C, Myrmel T. Nitric oxide synthase inhibition impairs myocardial efficiency and ventriculo-arterial matching in acute ischemic heart failure. Eur J Heart Fail 2004; 6: 705-713.

28. Huang SS, Wei FC, Hung LM. Ischemic preconditioning attenuates postischemic leukocyte-endothelial cell interactions: Role of nitric oxide and protein kinase C. Circ J 2006; 70: 1070-1075.

29. Hare JM, Loh E, Creager MA, Colucci WS. Nitric oxide inhibits the positive inotropic response to $\beta$-adrenergic stimulation in humans with left ventricular dysfunction. Circulation 1995; 92: 2198-2203.

30. Lenihan DJ, Gerson MC, Hoit BD, Walsh RA. Mechanisms, diagnosis, and treatment of diastolic heart failure. Am Heart J 1995; 130: $153-166$.

31. Atherson JJ, Moore TD, Lele SS, Thompson HL, Galbraith AJ, Belenkie I, et al. Diastolic ventricular interaction in chronic heart failure. Lancet 1997; 349: 1720-1724.

32. Kass DA, Beyer R, Lankford E, Heard M, Maughan WL, Sagawa K. Influence of contractile state on curvilinearity of in situ end-systolic pressure-volume relations. Circulation 1989; 79: 167-178.

33. Ikeda Y, Biro S, Kamogawa Y, Yoshifuku S, Eto H, Orihara K, et al. Repeated sauna therapy increases arterial endothelial nitric oxide synthase expression and nitric oxide production in cardiomyopathic hamsters. Circ J 2005; 69: 722-729. 